\title{
Impact of due dates for complex product engineering change based on capability constraints
}

\author{
HuaiGuo Zhang ${ }^{1, a}$, Xiang Su, ${ }^{2, b}$, ZhiYing Wang ${ }^{3, c}$ \\ ${ }^{1}$ zhenjiang, jiangsu, China, Jiangsu university of science and technology \\ ${ }^{2}$ zhenjiang, jiangsu, China, Jiangsu university of science and technology \\ ${ }^{3}$ zhenjiang, jiangsu, China, Jiangsu university of science and technology

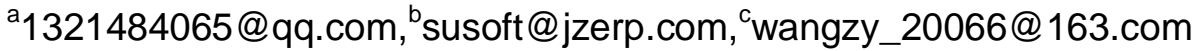

Keywords: complex product; engineering change; due dates; capacity constraints

\begin{abstract}
It is difficult to establish the delivery date during complex product engineering change, a model of the effect of delivery date based on capacity constraints was proposed. Firstly, capacity requirements plannings were set up according to the critical process of change parts manufacturing and the corresponding critical resources, and the critical resource load rate was calculated for evaluating load of resources categories. Then, using adjusted network diagram analyzes product delivery date change. Finally, a case study of complex product engineering changes was provided to validate the feasibility of the proposed method.
\end{abstract}

\section{Introduction}

In order to enhance product performance or meet the unique needs of customers, enterprises often occur in engineering changes in the product design and production process, especially products which the production cycle is longer and the structure of the product is complex[1]. To ensure on-time delivery companies are generally designing products to modify products, which makes engineering changes occur frequently. Engineering changes are accompanied by changes in resource requirements, and if the resource requirements exceed a limit, it will produce a bottleneck to limit the output and result in delays in delivery. Product delivery is related to customer satisfaction with the enterprise, and delivery according to the contract agreed is conducive to establish a good image of the enterprise[2]. Therefore, it is necessary to strengthen the control of the product manufacturing process so that we can assess the impact of change to obtain a more feasible delivery. However, due to the changing risk, the process of change parts and the required equipment capacity, it is difficult for enterprises to obtain an accurate delivery time when engineering change occurs. Therefore, the establishment of an effective method to be used to analyze the impact of engineering change on the delivery date of the product has important practical significance.

\section{Analysis model of engineering change on delivery time}

An engineering change is defined as a modification to the product or its parts on its design, materials, functions and other aspects after initial design. For a specific product, it can be mapped to one or more parts modification whether it is specific or fuzzy change description. Complex products are typical small batch production, and the number of parts is more, and the relationship between parts is miscellaneous. A change on single parts will cause multiple parts affected. Therefore, we can achieve the implementation, dissemination, release and tracking of the engineering change based on product structure, and the specific process is shown in Figure 1. 


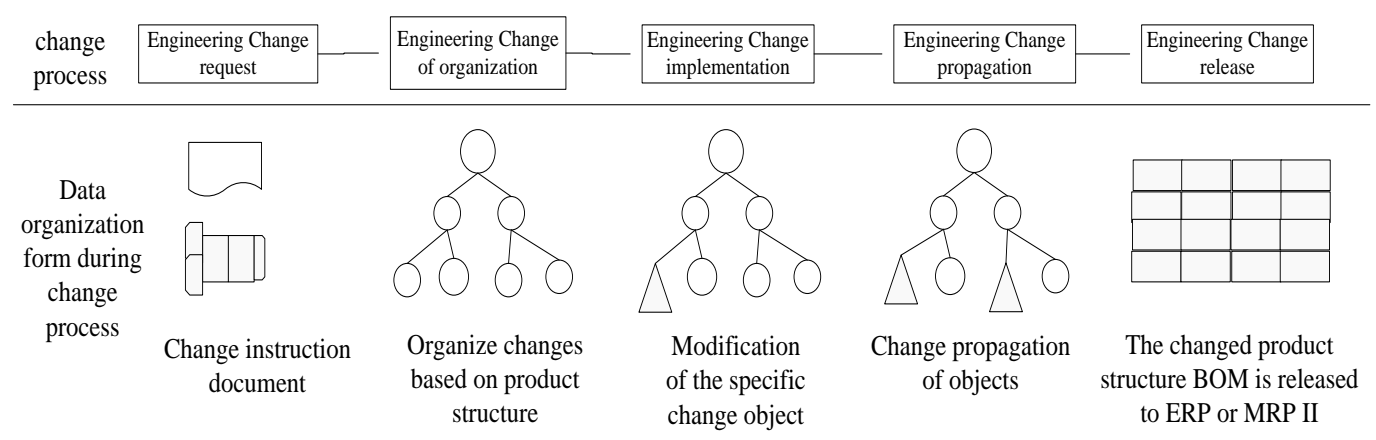

Fig. 1. Engineering change information transfer process

From Figure 1, it can be found that the information transfer of engineering change will eventually be reflected in the BOM file of the product. BOM is the data source of ERP, and it also records all the information in the production process[3]. The BOM information contains the assembly information of the product, the raw materials of parts, tooling tools, manufacturing processes and assembly process and so on, and it is the follow-up manufacturing data source. Wentao Yang et al. [4]contrasted the effectiveness of the version of BOM to determine the change parts; Li Wan et al. proposed change inspection function to obtain engineering change data from PDM system to the manufacturing workshop.

Engineering changes are accompanied by resource requirements changes. If the resource load exceeds a capacity limit, it will produce a bottleneck to limit the output and result in delays in delivery[5]. Therefore, this paper presents an delivery time analysis model based on resource capacity constraints to analyze the impact of engineering change on product delivery time. The model is shown in Figure 2:

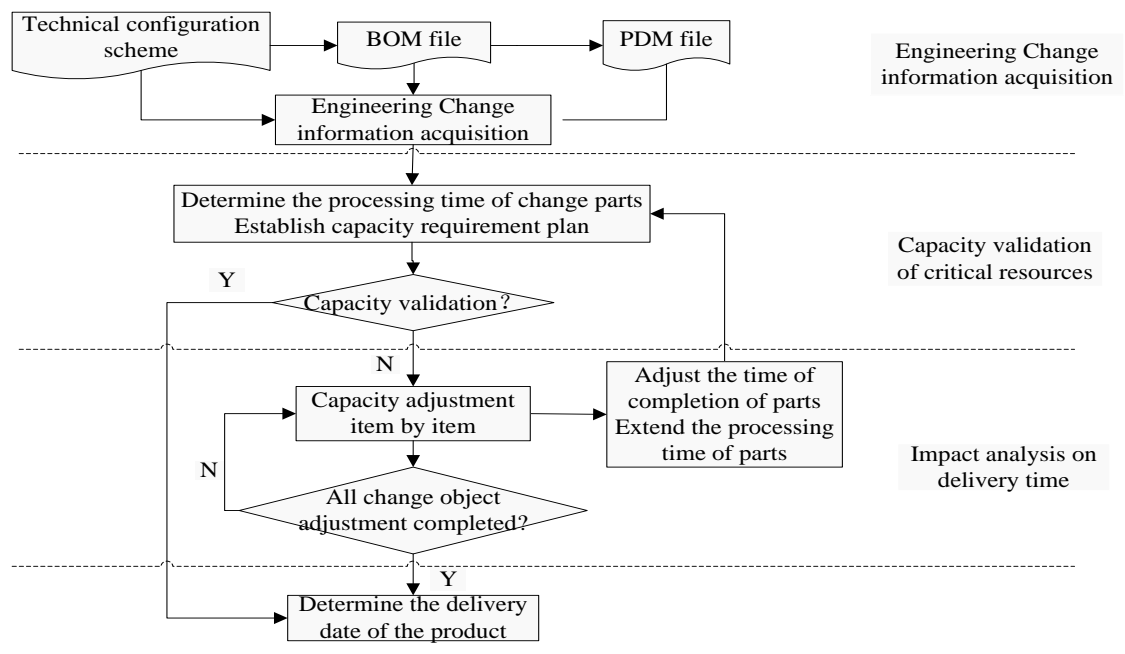

Fig. 2. Complex product engineering change delivery time impact analysis model

\section{Preparing the plan of change parts based on capacity constraints}

Engineering changes make the capacity requirements change for manufacturing resources. However, the manufacturing workshop production capacity is limited in a certain period, and we need to establish capacity requirements schedule by product BOM to find out overloaded equipment and adjust the load further.

\subsection{Establish capacity requirements plan}

\subsubsection{Definition and calculation of resource sets}

In general, the parts of the complex product are a high degree of customization and different parts are different in structure, function or size, so the processing for each part is also different. Only the equipment resources with the same or similar technical performance can meet the 
production needs and become the critical factor which influences the delivery of the product. Therefore, the critical resources used in the critical processes of the parts production are summed up to form a series of the resource set. The capacity constraints mainly come from the capacity output of this part of the critical resources denoted as $R_{i}(i=1,2, \ldots n)$. Each resource set $R_{i}$ daily maximum load or available capability $\mathrm{F}_{\mathrm{Ri}}$ is calculated as follows:

$$
F_{R_{i}}=\sum_{i=1}^{M} C_{K} T_{K} \eta_{i}
$$

$\mathrm{C}_{\mathrm{k}}$ is the production schedule of the resource set daily; $T_{k}$ is the duration of each schedule; $\mathrm{M}$ is the number of equipment in the resources set; $\eta_{\mathrm{i}}$ is the efficiency of each equipment.

\subsubsection{Capacity requirements calculation model of critical process}

According to the actual situation of the production, the process of parts will not stop until the whole process is complete. Therefore, we assume that each critical process can be completed only by a resource set $R_{i}$. Due to many factors influence the engineering change process, the duration of each process has strong uncertainty, and the possible duration of each critical process can only be calculated based on the experience of the production personnel and the statistics of a large number of historical data[6]. We intend to use the weighted average method to deal with statistical data in this paper:

$$
\mathrm{TO}_{\mathrm{R}_{\mathrm{i}}}=\frac{\sum_{\mathrm{i}=1}^{\mathrm{m}}\left(\mathrm{TO}_{\mathrm{i}}^{\mathrm{R}_{\mathrm{i}}}\right)^{2}}{\sum_{\mathrm{i}=1}^{\mathrm{m}}\left(\mathrm{TO}_{\mathrm{i}}^{\mathrm{R}_{\mathrm{i}}}\right)} \quad \text { (2) } \quad \mathrm{TL}_{\mathrm{R}_{i}}=\frac{\sum_{\mathrm{i}=1}^{\mathrm{m}} \mathrm{TL}_{\mathrm{i}}^{\mathrm{R}_{i}} \times \mathrm{TO}_{\mathrm{i}}^{\mathrm{R}_{\mathrm{i}}}}{\sum_{\mathrm{i}=1}^{\mathrm{m}} \mathrm{TL}_{\mathrm{i}}^{\mathrm{R}_{i}}}
$$

$T O_{R i}$ is the weighted average of the processing time in the resource set $R_{i}$ for a process; TL $L_{R i}$ is the weighted average of the production in the resource set $\mathrm{R}_{\mathrm{i}}$; $\mathrm{TO}_{\mathrm{i}}^{\mathrm{Ri}}$ is the weighted average of the processing time for the sample $i$ in the resource set $R_{i}$; $T L_{i}{ }^{R i}$ is the production cycle for the sample $i$ in the resource set $\mathrm{R}_{\mathrm{i}}$; $\mathrm{m}$ is the number of statistical samples. With the number of samples increased, the calculated value of corresponding production cycle and processing duration are closer to the actual value, and the error generated by the weighted average method can be ignored.

\subsection{Classification and computation of resources load}

Product manufacturing process is essentially the process of load conversion, a load of relevant resources carrying during production process can be divided into fixed load and variable load. Not all resources used in the manufacturing workshop are the resources that may be used by the critical process of the parts to be programmed. We only consider the same as the critical resource used to change the production of the parts of a load of resources. We need to determine the planned changes parts all critical processes in the processing period and calculate the capacity requirements of corresponding resources set using the critical process capacity requirements calculation model, then the fixed load of resources set can be determined. A small amount of load released during the engineering change can also be used as part of the fixed load. In addition to the planned changes parts, it may exist in the production of other parts within the same period, the resulting load of these parts is variable with upper and lower bounds due to the uncertainty of the opening time. Rough production plan is formulated according to the method of rounding and reverse platoon.

In the process of change parts, we need to determine the same resources requirements between critical processes for all other parts and change parts so that the capacity requirements of all components can be obtained in the same processing period. the corresponding load is superimposed according to the resource set. This paper measures the load condition of the resources set by critical resource load rate[7]:

$$
\begin{aligned}
& \left.\mathrm{I}_{\mathrm{i}}, \mathrm{t}\right)=\frac{\mathrm{CRS}_{\text {max }}\left(\mathrm{R}_{\mathrm{i}}, \mathrm{t}\right)-\mathrm{CDO}\left(\mathrm{R}_{\mathrm{i}}, \mathrm{t}\right)}{\mathrm{CRS}_{\text {max }}\left(\mathrm{R}_{\mathrm{i}}, \mathrm{t}\right)-\mathrm{CRS}_{\min }\left(\mathrm{R}_{\mathrm{i}}, \mathrm{t}\right)} \quad \text { (4) } \quad \mathrm{CDO}\left(\mathrm{R}_{\mathrm{i}}, \mathrm{t}\right)=\sum_{\mathrm{j}=1}^{\mathrm{n}} \mathrm{tC}_{\mathrm{M}_{\mathrm{j}}} \\
& \mathrm{CRS}_{\text {max }}\left(\mathrm{R}_{\mathrm{i}}, \mathrm{t}\right)=\mathrm{FL}\left(\mathrm{R}_{\mathrm{i}}, \mathrm{t}\right)+\mathrm{B}_{\text {max }}\left(\mathrm{R}_{\mathrm{i}}, \mathrm{t}\right) \quad \text { (6) } \quad \mathrm{CRS}_{\text {min }}\left(\mathrm{R}_{\mathrm{i}}, \mathrm{t}\right)=\mathrm{FL}\left(\mathrm{R}_{\mathrm{i}}, \mathrm{t}\right)+\mathrm{B}_{\text {min }}\left(\mathrm{R}_{\mathrm{i}}, \mathrm{t}\right)
\end{aligned}
$$

$I\left(R_{i}, t\right)$ is the critical resource load rate of $R_{i}$ in the t period; $C D O\left(R_{i}, t\right)$ is the available capacity of $R_{i}$ in the $t$ period, which is the sum of the available capabilities $F_{R i}$ of the $n$ facilities in $R_{i}$ in the $t$ 
period; $\operatorname{FL}\left(\mathrm{R}_{\mathrm{i}}, t\right)$ is the fixed load of $\mathrm{R}_{\mathrm{i}}$ in the t period; $B_{\max }\left(\mathrm{R}_{\mathrm{i}}, \mathrm{t}\right)$ is upper bound of the variable load $R_{i}$ in the $t$ period; $B_{\min }\left(R_{i}, t\right)$ is the lower bound of the variable load $R_{i}$ in the $t$ period. Here, we introduced the maximum acceptable load rate $I_{\max }\left(R_{i}, t\right)$, the value of $I_{\max }\left(R_{i}, t\right)$ is equal to 1 in general, then the lower bound load $C R S_{\min }\left(\mathrm{R}_{\mathrm{i}}, \mathrm{t}\right)$ is equal to the available capacity $\operatorname{CDO}\left(\mathrm{R}_{\mathrm{i}}, \mathrm{t}\right)$. For different production systems, we can set different maximum acceptable load rate $I_{\max }\left(R_{i}, t\right)$. According to $I_{\max }\left(R_{i}, t\right)$, the critical resource load rate $I\left(R_{i}, t\right)$ can be divided into different ranges:

1. If $\mathrm{CRS}_{\max }\left(\mathrm{R}_{\mathrm{i}}, \mathrm{t}\right)=C R S_{\min }\left(\mathrm{R}_{\mathrm{i}}, \mathrm{t}\right)$, the resource load does not have the change range, to ensure the meaning of the formula, we take $\operatorname{CDO}\left(\mathrm{R}_{\mathrm{i}}, \mathrm{t}\right)$ as the denominator. When $\mathrm{I}\left(\mathrm{R}_{\mathrm{i}}, \mathrm{t}\right) \leq 0$, $\mathrm{CRS}_{\min }\left(\mathrm{R}_{\mathrm{i}}, \mathrm{t}\right) \leq \mathrm{CDO}\left(\mathrm{R}_{\mathrm{i}}, \mathrm{t}\right)$, the resource load is not overloaded; When $\mathrm{I}\left(\mathrm{R}_{\mathrm{i}}, \mathrm{t}\right) \geq 0, \mathrm{CRS}_{\min }\left(\mathrm{R}_{\mathrm{i}}, \mathrm{t}\right) \geq \mathrm{CDO}$ $\left(R_{i}, t\right)$, the resource load is overloaded and need to be adjusted.

2. If $\mathrm{CRS}_{\max }\left(\mathrm{R}_{\mathrm{i}}, \mathrm{t}\right) \neq C \mathrm{CRS}_{\min }\left(\mathrm{R}_{\mathrm{i}}, \mathrm{t}\right)$, when $\mathrm{I}\left(\mathrm{R}_{\mathrm{i}}, \mathrm{t}\right) \leq \mathrm{I}\left(\mathrm{R}_{\mathrm{i}}, \mathrm{t}\right) \leq 0, \mathrm{CRS}_{\max }\left(\mathrm{R}_{\mathrm{i}}, \mathrm{t}\right) \leq \mathrm{CDO}\left(\mathrm{R}_{\mathrm{i}}, \mathrm{t}\right)$, the resource load is not overloaded and is not to be adjusted; when $0 \leq \mathrm{I}\left(\mathrm{R}_{\mathrm{i}}, \mathrm{t}\right) \leq \mathrm{I}_{\max }\left(\mathrm{R}_{\mathrm{i}}, \mathrm{t}\right)$, then $\mathrm{CRS}_{\max }$ $\left(R_{i}, t\right) \geq \operatorname{CDO}\left(R_{i}, t\right)$, the resource load may be overloaded; when $I\left(R_{i}, t\right) \geq I_{\max }\left(R_{i}, t\right)$, then $\mathrm{CRS}_{\text {min }}\left(\mathrm{R}_{\mathrm{i}}, \mathrm{t}\right) \geq \operatorname{CDO}\left(\mathrm{R}_{\mathrm{i}}, \mathrm{t}\right)$, the resource load is overloaded and the resources are bottleneck resources, and the corresponding capacity adjustment is needed.

\section{Analyzing delivery change based on network diagram}

\subsection{The basic idea of capacity adjustment}

The resource bottlenecks resulting from engineering changes lead to advance or delay in the production schedule of each component, which further affects the final delivery date of the product[8]. According to the calculation formula of critical resource load rate, we can calculate the overload and less load of the manufacturing workshop and find out the bottleneck resources. If the capacity and the load is not balanced, we can repeatedly take measures to adjust the opening time or extend the processing period until the critical resource load rate is within acceptable limits.

\subsection{Analysis on the impact of engineering change on delivery}

The network diagram shows the schedule of each component of the product, the longest path in the network is called the critical path. The parts on the critical path are called critical components, The completion time of the last critical component is the product lead time. For example, a-i-j-c is the critical path in figure $3, \mathrm{j}$ is the tight part of $\mathrm{i}$ and $\mathrm{k}$.

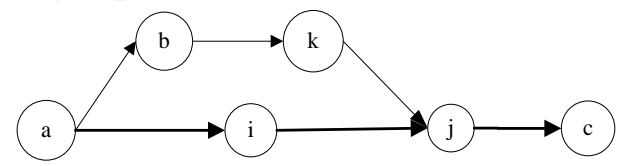

Fig. 3. Product production network plan

If $i$ is the change parts, the adjusted completion time of $i$ is $T F_{i}^{\prime}=T S_{i}^{\prime}+T_{i}^{\prime}, T S_{i}^{\prime}$ and $T_{i}^{\prime}$ represent start time and duration of i respectively after the change. If $T F_{i}^{\prime} \geq T F_{i}$, the completion period of $j$ is $\mathrm{TF}_{\mathrm{j}}^{\prime}=\mathrm{TF}_{\mathrm{i}}^{\prime}+\mathrm{T}_{\mathrm{j}} \geq \mathrm{TF}_{\mathrm{j}}$, and the completion period of all latter critical parts are required to delay correspondingly; If $\mathrm{TF}_{\mathrm{i}} \leq \min \left(\mathrm{TF}_{\mathrm{i}} \mathrm{TF}_{\mathrm{k}}\right)$, the adjusted completion time of $\mathrm{i}$ is earlier than the earliest completion time of $\mathrm{k}$ on the non-critical path, then the k-correspondence of the non-critical path turn into the critical path, the completion time of $\mathrm{j}$ is $\mathrm{TF}_{\mathrm{j}}^{\prime}=\mathrm{TF}_{\mathrm{k}}{ }_{\mathrm{k}}+\mathrm{T}_{\mathrm{j}}$, if $\mathrm{TF}_{\mathrm{k}} \leq \mathrm{TF}_{\mathrm{i}} \leq \mathrm{TF} \mathrm{F}_{\mathrm{i}}$, the completion time of $\mathrm{j}$ is $\mathrm{TF}_{\mathrm{j}}^{\prime}=\mathrm{TF}^{\prime}{ }_{\mathrm{i}}+\mathrm{T}_{\mathrm{j}}$.

Similarly, if $\mathrm{k}$ is the change parts and $\mathrm{k}$ is in non-critical path. if $\mathrm{TF}_{\mathrm{k}}{ }^{\prime} \leq \mathrm{TF}_{\mathrm{k}}$, the component $\mathrm{k}$ is finished in advance, it will only affect the completion time of the follow-up parts on the non-critical path and will not have impact on the product delivery and critical path; if $\mathrm{TF}_{k}{ }_{\mathrm{k}} \geq \max \left(T F_{\mathrm{i},} \mathrm{TF}_{\mathrm{k}}\right)$, the adjusted completion time of $\mathrm{j}$ is $\mathrm{TF}_{\mathrm{j}}{ }^{\prime}=\mathrm{TF}^{\prime}{ }_{k}+\mathrm{T}_{\mathrm{j}} \geq \mathrm{TF}_{\mathrm{j}}$, the k-correspondence of the non-critical path turns into the critical path, and the completion time of subsequent parts put off; if not, it will only delay the completion time of latter parts on non-critical path, and the delivery and critical path will not have an impact. We can push back until the last critical parts, and its completion time is the product delivery after engineering change. 


\section{Case study}

We take a product with 20 parts which are numbered 1-20 for example. The network diagram is shown in Figure 4, and the initial critical path is 1-2-4-6-8-9-10-12-16-18-19-20, the product will be completed on the 90th day. In order to improve the performance of the product enterprise need to operate engineering change, and we can access to engineering change parts set $\{3,4,9,11,13\}$ by the version of product BOM comparison and PDM system inspection. In order to simplify the analysis process, we here only take the change part 4 as an example to illustrate the model and the rest change parts are for similar treatment. Parts 4 will be produced at 6 and be completed within 10 days, and parts 5 and parts 7 parallel processing in the same period.

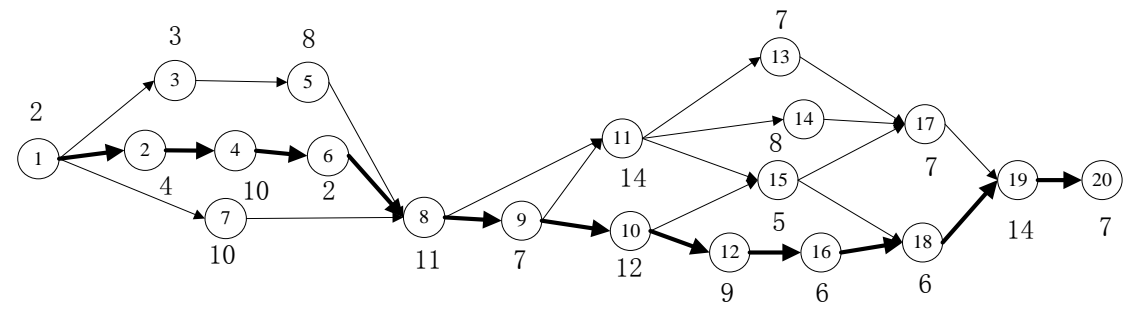

Fig. 4. Component production network diagram

According to the manufacturing process of the parts 4 , the critical processes are $R_{1}, R_{2}, R_{3}, R_{4}$. We assume that the fixed load is known in manufacturing workshop, the capacity requirements and processing cycle of critical components can be obtained from the previous statistical data and calculation model, as shown in Table 1:

\begin{tabular}{|c|c|c|c|c|c|}
\hline Change parts & Load category & $\mathrm{R}_{1}$ & $\mathrm{R}_{2}$ & $\mathrm{R}_{3}$ & $\mathrm{R}_{4}$ \\
\hline \multirow{4}{*}{4} & Available capacity (h) & 80 & 100 & 80 & 50 \\
\cline { 2 - 6 } & Fixed load (h) & 50 & 72 & 46 & 38 \\
\cline { 2 - 6 } & Capacity requirements (h) & 8 & 12 & 15 & 4 \\
\cline { 2 - 6 } & load released (h) & 0 & 2 & 0 & 0 \\
\hline \multirow{3}{*}{5} & Capacity requirements (h) & 9 & 9 & 5 & 4 \\
\cline { 2 - 6 } & load released (h) & 0 & 0 & 0 & 0 \\
\hline \multirow{2}{*}{7} & Capacity requirements (h) & 6 & 30 & 8 & 6 \\
\cline { 2 - 6 } & load released (h) & 0 & 6 & 4 & 2 \\
\hline
\end{tabular}

Tab. 1 . The capacity requirements of change parts to resource sets

The rough production plan for the three parts 4, 5, 7 can be developed in a row and reverse plan, and the Gantt chart is shown in Figure 5.

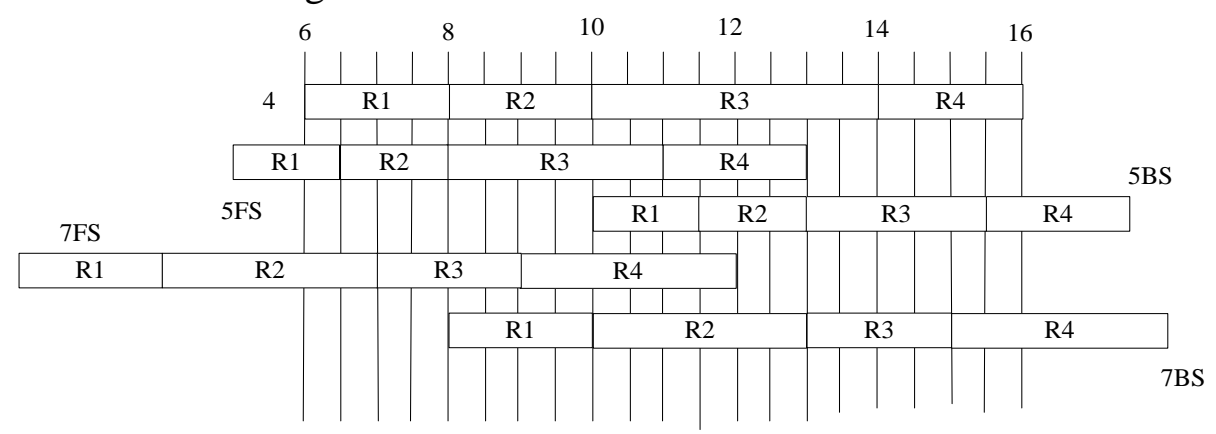

Fig. 5. Gantt chart of change parts 4

According to Table 1 and Figure 7 the critical resource load rate of each resource set $R_{i}$ can be calculated. Take $\mathrm{R}_{1}$ as an example and the calculation process is as follows:

For the parts 4 , the processing time of $R_{1}$ is 2 days and the capacity requirement is 8 hours, and the row and reverse row planning time are $B_{\max }=B_{\min }=8$ hours according to Gantt Figure 7; for the parts 5 , the processing time of $R_{5}$ is 1.5 days and the capacity requirement is 9 hours, and then the reverse plan $B_{\max }=9$ hours and the plan $B_{\min }=9 \div 3 \times 2=6$ hours; for the parts 7 , the processing time of $R_{7}$ is 2 days and the capacity requirement is 6 hours, and then the reverse plan 
$\mathrm{B}_{\max }=0$ hours and the plan $\mathrm{B}_{\min }=6$ hours. Therefore, $\mathrm{CRS}_{\max }=50+(8+9+6)=73$ hours, $\mathrm{CRS}_{\min }$ $=50+(8+6+0)=64$ hours, then $I\left(R_{1}, t\right)=0.238$. Other resource sets $R_{2}, R_{3}, R_{4}$ are similar , the final calculation results are shown in Table 2.

\begin{tabular}{|c|c|c|c|c|}
\hline Indicators & $\mathrm{R}_{1}$ & $\mathrm{R}_{2}$ & $\mathrm{R}_{3}$ & $\mathrm{R}_{4}$ \\
\hline $\mathrm{CRS}_{\max }\left(\mathrm{R}_{\mathrm{i}}, \mathrm{t}\right)$ & 85 & 131 & 68 & 52 \\
\hline $\mathrm{CRS}_{\min }\left(\mathrm{R}_{\mathrm{i}}, \mathrm{t}\right)$ & 64 & 111 & 68 & 48 \\
\hline $\mathrm{I}\left(\mathrm{R}_{\mathrm{i}}, \mathrm{t}\right)$ & 0.238 & 1.55 & -0.15 & 0.57 \\
\hline
\end{tabular}

Tab. 2. Critical resource load rate

The value of $I_{\max }\left(R_{i}, t\right)$ is 1 .The critical resource load rate of $R_{2}$ is greater than 1 so that $R_{2}$ become a bottleneck resource. Therefore, it is necessary to take appropriate capacity adjustment measures to make part 4 meet the production capacity of the workshop, such as extending the processing time. In this case, the final method is to extend the completion time of parts 4 from 16 to 20 days, and the delivery date of the product is on the 94th day according to the network diagram 1.At this point, the impact of Change part 4 on the delivery time is completed. Assuming that the critical resource load rate is used, the capacity adjustment of all change parts is shown on Table 3:

\begin{tabular}{|c|c|c|c|c|}
\hline $\begin{array}{c}\text { Change } \\
\text { parts }\end{array}$ & $\begin{array}{c}\text { original } \\
\text { duration }\end{array}$ & $\begin{array}{c}\text { Changed } \\
\text { duration }\end{array}$ & $\begin{array}{c}\text { Changed } \\
\text { delivery time }\end{array}$ & Critical path \\
\hline 3 & 3 & 6 & 90 & $1-2-4-6-8-9-10-12-16-18-19-20$ \\
\hline 4 & 10 & 14 & 94 & $1-2-4-6-8-9-10-12-16-18-19-20$ \\
\hline 9 & 7 & 5 & 92 & $1-2-4-6-8-9-10-12-16-18-19-20$ \\
\hline 11 & 14 & 22 & 96 & $1-2-4-6-8-9-11-14-17-19-20$ \\
\hline 13 & 7 & 5 & 96 & $1-2-4-6-8-9-11-14-17-19-20$ \\
\hline
\end{tabular}

Tab. 3. Changed schedule in parts to adjust the way and changes in delivery

Figure 6 shows the new production network diagram after the change, and the critical path is 1-2-4-6-8-9-11-14-17-19-20 and the final product delivery time is 96th days.

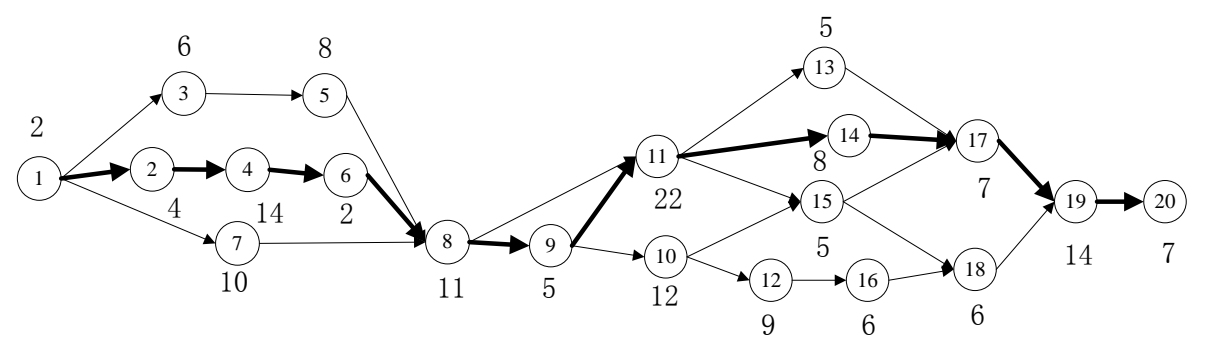

Fig. 6. The adjusted network diagram of change parts

\section{Conclusion}

Delivery is one of the main objectives of product management. The frequent occurrence of engineering changes has caused great disturbance to the production plan of the product, and shortage of resources is also the main reason for the delay in delivery. The model this paper proposed takes the resources capacity into consideration and overcomes the deficiency of traditional method to delivery analysis. However, this paper only considers the impact of the change in the capacity demand on the delivery time caused by the engineering change, and thus has some limitations. In practice, enterprise can take overtime or other means to speed up production, which involves the relationship between engineering change costs and delivery time, and it is worth further study.

\section{Acknowledgement}

This research has been funded by National Science Foundation of China (No. 71471078), Humanities and Social Science Research Projects in Ministry of Education of China (No. 16YJA630056). 


\section{Reference}

[1] Rui He, Dunbing Tang, Jianbin Xue. Engineering change propagation based on design structure matrix[J]. Computer Integrated Manufacturing System, 2008,14 (4): 656-660

[2] Jikun Wang, Fajie Wei. Analysis and Evaluation of the Impacts on Engineering Change[J]. Industry Engineering, 2006,9 (3): 32-35

[3] Xiang Su, Yanhua Pan, Xuanxi Ning. research based on incremental MBOM large small batch production received[J]. Chinese Management Science 2004,12 (2): 73-77

[4] Wentao Yang, Sheng Leng. On Matrix-based Version Validity of Bills of Material in an Aircraft Manufacturing Execution System[J].. Mechanical Science and Technology, 2011,30 (8): 1248-1251

[5] Qian Yu, Shiliang Jin, Wenzhong He. Optimization and detection of bottleneck in production based on TOC and OTE[J]. Mechanical Design and Manufacture, 2011 (9): 182-184

[6] Guangming Zhou. Research on optimizing production activity planning and control with small-batch product [J]. Modern Manufacturing Engineering, 2010,10 (5): 38-43

[7] Donatella Corti, Alessandro Pozzetti, Marta Zorzini. A capacity-driven approach to establish reliable due dates in a MTO environment[J]. Int.Production Economic 104(2006):536-554

[8] Shuyun Wang, Xiangsong Zhu, Jie Li. Research of A Step-by-Step CPM Base on Resource-Constrained[J]. Journal of Management Engineering, 2006,01 (23): 109-111 